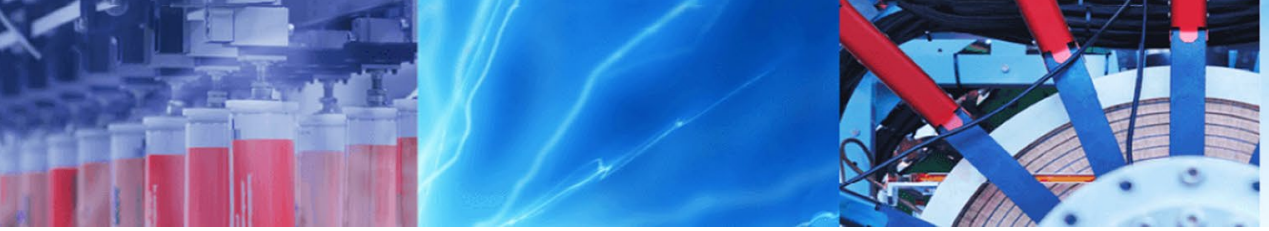

Research Article

\title{
A cost-effective method for robust and anti-corrosive superhydrophobic coatings
}

\author{
Yanfen Huang ${ }^{1}\left[\right.$ B $\cdot$ Bin Chen ${ }^{1} \cdot$ Zaosheng $\mathrm{Lv}^{1} \cdot$ Fen Guo $^{1} \cdot$ Chi Huang $^{2}$
}

(c) Springer Nature Switzerland AG 2019

\begin{abstract}
In this work, we developed a simple method to fabricate robust and anti-corrosive superhydrophobic coatings. The multiscale nano/microstructures were induced by styrene-butadiene-styrene and two kinds of nanoparticles of $\mathrm{SiO}_{2}$ and $\mathrm{TiO}_{2}$. The unique hierarchical structures contribute to the superhydrophobic coatings with a remarkable water contact angle of $154.4^{\circ}$ and contact angle hysteresis of $2.1^{\circ}$. In particular, the superhydrophobic coatings exhibited excellent thermal stability, mechanical stability and self-cleaning property. The synergistic effect of $\mathrm{SiO}_{2}$ nanoparticles and $\mathrm{TiO}_{2}$ nanoparticles could improve corrosion resistance of the superhydrophobic coatings. The superhydrophobic coatings retained their original superhydrophobicity when directly soaked in $3.5 \mathrm{wt} . \% \mathrm{NaCl}$ solution for 3 days. The electrochemical experiments show that the superhydrophobic coatings can significantly improve the corrosion resistance of aluminum plate. Furthermore, the superhydrophobic coatings were applied to oil/water separation. The superhydrophobic coatings give a promising prospect for practical applications in a broad range of fields based on their large-scale and low-cost fabrication method.
\end{abstract}

Keywords Superhydrophobic · Robust · Anti-corrosion · Self-cleaning

\section{Introduction}

Over the past few decades, superhydrophobic surfaces with a water contact angle (WCA) over $150^{\circ}$ and a sliding angle lower than $10^{\circ}$ have attracted considerable attention due to their wide applications, such as oil/water separation [1-5], self-cleaning [6-8], corrosion resistance [9-12], antiicing [13-15], anti-fogging [16, 17], anti-bacterial [18, 19], drag reduction $[20,21]$ and so on. The wettability of the solid surface is a special property, governed by surface free energy and geometrical structure. By research, the WCA of a material even with the lowest surface energy such as polytetrafluoroethylene will not exceed $120^{\circ}$ if the surface is smooth $[22,23]$. Inspired by lotus leaves in nature, researchers have recognized that the coexistence of low surface energy and hierarchical structure is key for realizing a superhydrophobic surface. A large number of methods have been reported to fabricate superhydrophobic surfaces, but most of which, require tedious procedures or high costs [24]. In addition, poor mechanical properties are serious and common problems in superhydrophobic surfaces, limiting their practical applications $[25,26]$. Therefore, the preparation of robust superhydrophobic surfaces is very important to the practical application of the superhydrophobic products. Until now, ensuring that preparation processes for superhydrophobic surfaces are cheap, fast, simple, and feasible remains challenging for practical applications.

Electronic supplementary material The online version of this article (https://doi.org/10.1007/s42452-019-0620-3) contains supplementary material, which is available to authorized users.

Yanfen Huang, huangyanfen@wust.edu.cn | ${ }^{1}$ Hubei Key Laboratory of Coal Conversion and New Carbon Material, School of Chemistry and Chemical Engineering, Wuhan University of Science and Technology, Wuhan 430081, China. ${ }^{2}$ College of Chemistry and Molecular Sciences, Wuhan University, Wuhan 430072, China.

SN Applied Sciences (2019) 1:612 | https://doi.org/10.1007/s42452-019-0620-3 
Fluorocarbon materials are commonly employed to fabricate superhydrophobic coatings due to their inherent low surface energy [27-29], however, which are usually expensive and potentially damaged to the environments. Other materials with low surface energy are used to replace the fluorocarbons, such as polydimethylsiloxane $[30,31]$, polyacrylate $[32,33]$, polyethersulfone [34, 35], polyvinylidene fluoride [36] and polybenzoxazine [37]. As a thermoplastic elastomer, styrene-butadiene-styrene (SBS) triblock copolymers have two-phase morphology of spherical polystyrene block domains within matrix of polybutadiene. SBS are the world's largest production and most similar to rubber performance, with low costs, and widely used in building $[38,39]$. As far as we know, SBS is rarely used in the preparation of superhydrophobic coatings. Considering SBS possesses excellent tensile strength, good chemical resistance and outstanding low temperature property, it is a kind of excellent polymer which can be applied to construct superhydrophobic coatings.

Corrosion is the main cause of the damage and abandonment of various infrastructure and industrial equipment. Corrosion losses are internationally recognized as more than the total loss of all natural disasters. Using the hydrophobicity of superhydrophobic materials to block substrate contact with corrosive medium can reduce the corrosion of metals [40]. Ren et al. [41] prepared superhydrophobic surface by passivated $\mathrm{ZnO}$ and polydimethylsiloxane for metal corrosion protection. Aluminium and its alloys are widely used in various fields due to their low density, low cost, good conductivity in electricity and heat, high plasticity. Unfortunately, they are prone to corrosion in harsh conditions.

The organic-inorganic hybrid method is one of the most promising methods for fabricating superhydrophobic surfaces due to its low demand for equipment, simple operation, low cost, which is feasible for large-scale commercial applications [42]. In this study, two kinds of nanoparticles of $\mathrm{SiO}_{2}$ and $\mathrm{TiO}_{2}$ were used together to fabricate superhydrophobic coatings. The multi-scale nano/microstructures were obtained by mixing SBS and these two kinds of nanoparticles. The fabricated superhydrophobic coatings shows WCA of $154.4^{\circ}$ and contact angle hysteresis of $2.1^{\circ}$. The superhydrophobic coatings exhibited excellent thermal stability, mechanical stability and self-cleaning property. The superhydrophobic coatings retained their original superhydrophobicity when directly soaked in $3.5 \mathrm{wt} . \% \mathrm{NaCl}$ solution for 3 days. The electrochemical experiments show that the superhydrophobic coatings can significantly improve the corrosion resistance of aluminum plate. Moreover, the superhydrophobic coatings were applied to oil/water separation. The superhydrophobic coatings give a promising prospect for practical applications in a broad range of fields based on their large-scale and low-cost fabrication method.

\section{Experimental section}

\subsection{Materials}

Styrene-butadiene-styrene (SBS) $(\mathrm{YH}-791 \mathrm{H})$ was purchased from the Baling Petrochemical Company and was used as received. Silica sol (xylene) with a particle size of approximately $20 \mathrm{~nm}$ (30 wt.\%) was supplied by Wuhan Green Chemical Technology Co., Ltd. $\mathrm{TiO}_{2}$ nanoparticles (P25) were purchased from Germany AEROXIDE Company. Toluene, dichloromethane (DCM), $\mathrm{NaCl}$ and aluminium plate were purchased from Shanghai Chemical Reagents Company. Cotton cloth was purchased from local market.

\subsection{Preparation of superhydrophobic coatings}

Glass plates with a size of $2.5 \mathrm{~cm} \times 7.5 \mathrm{~cm}$ were used as substrates, ultrasonically cleaned in ethanol, rinsed with deionized water, and dried in stove as the preparative. SBS was dissolved in toluene and stirred for $1 \mathrm{~h}$ at room temperature, getting $10 \mathrm{wt} . \%$ SBS solution. Then, the composite solution was obtained by blending a certain amount of the silica sol (xylene), $\mathrm{TiO}_{2}$ nanoparticles, toluene and the as-prepared SBS solution by magnetic stirring for $30 \mathrm{~min}$. Total solid content of the composite solution was fixed at 5 wt.\%. Approximately $1.5 \mathrm{~mL}$ of the composite solution was casted to the glass substrate. Coatings with varied surface roughness were obtained after drying for $12 \mathrm{~h}$ at ambient temperature. The optimized superhydrophobic coating was applied on cotton cloth and aluminium plate, respectively. The optimized superhydrophobic coating was applied on a qualitative filter paper for oil/water separation. The coatings were prepared on a variety of substrates similar as on glass plates. Two sides of the aluminium plate were coated with the optimized superhydrophobic coating for electrochemical experiments.

\subsection{Characterization}

Water contact angle (WCA) was investigated by using DSA 100 (KRÜSS, Germany). Every water droplet was $5 \mu \mathrm{L}$. WCA was measured at ambient temperature by averaging six fresh points. Advancing and receding contact angles were measured during the growth and shrinkage of a droplet, respectively. The surface topography and surface chemical composition were analyzed by field emission scanning electron microscopy (FESEM, Nova NanoSEM400) and $X$-ray energy dispersive spectroscopy (EDS), respectively. Thermal gravimetric analysis (TGA) was performed on 
Fig. 1 The superhydrophobic coatings coated on glass plate (a), cotton cloth (b) and aluminium plate (c). Water droplets were dyed blue by methylene blue. The inset showing a $5 \mu \mathrm{L}$ distilled water drop profile on the superhydrophobic coatings
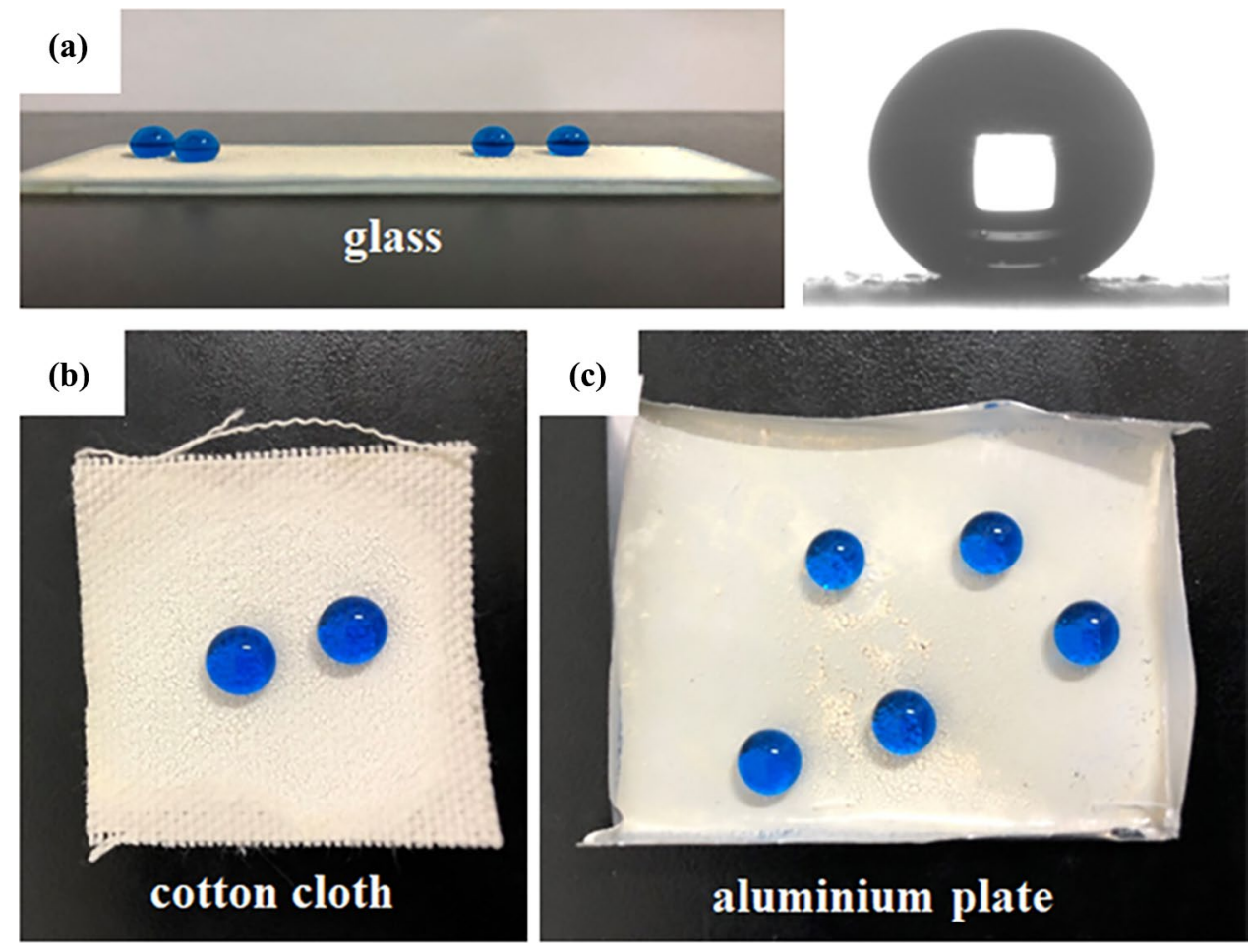
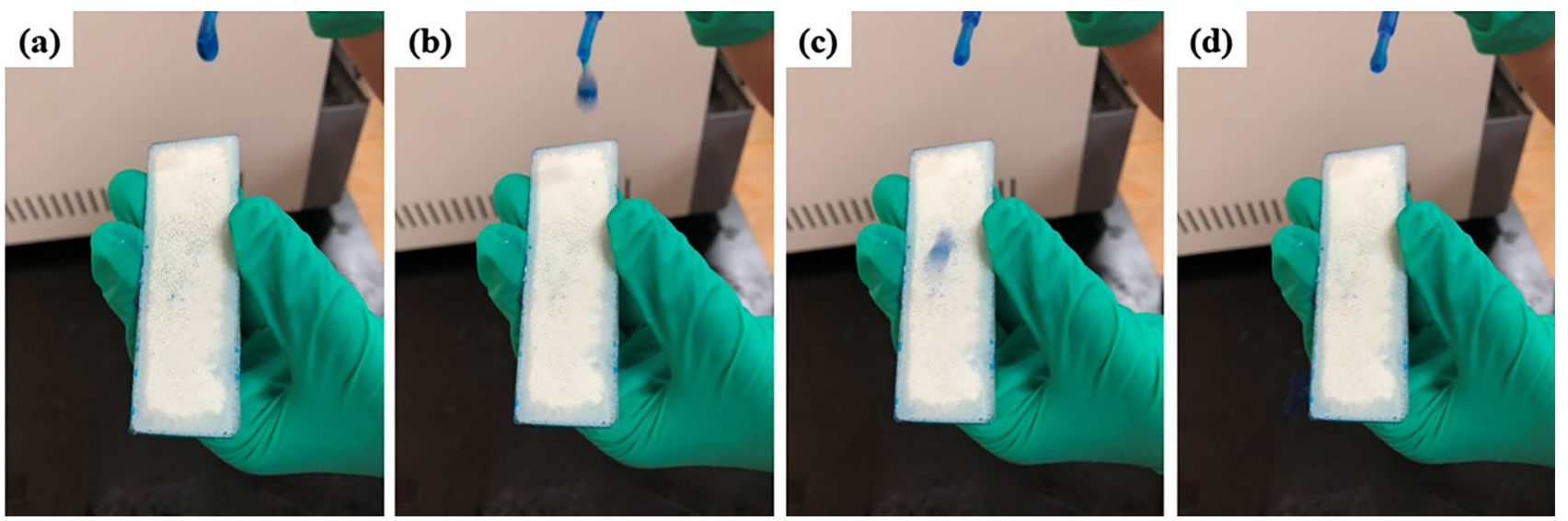

Fig. 2 The images illustrate water droplet bouncing on the tilted superhydrophobic coatings

NETZSCH F1 Libra ${ }^{\oplus}$ (TGA209F1D-0315-L). Approximately $10 \mathrm{mg}$ of the coatings were heated in an $\mathrm{Al}_{2} \mathrm{O}_{3}$ crucible in air atmosphere from ambient temperature to $500{ }^{\circ} \mathrm{C}$, with a constant heating rate of $10^{\circ} \mathrm{C} / \mathrm{min}$. To characterize the heat resistance of the superhydrophobic coatings, the superhydrophobic coatings applied to glass plates were placed in an electricity heat drum wind drying oven at $200^{\circ} \mathrm{C}$ for 3 days. To determine the self-cleaning property of the superhydrophobic coatings, the model contamination (river sand) was placed onto the surfaces of the superhydrophobic coatings, subsequently, the water droplets were dripped, the river sands were removed with water droplets rolled off the surfaces of the superhydrophobic coatings. The self-cleaning performance of the superhydrophobic coatings was recorded using a digital camera. To investigate water repellency of the superhydrophobic coatings in water, the outer surface of a square paper box with a side length of $3.6 \mathrm{~cm}$ folded by us was coated the superhydrophobic coatings. River sands were carefully added into the box until the box upper edges were close to the water surface. Then the river sands were weighted. Surface robustness was tested via transparent glue-paste, finger-touch, brush-sweep tests and sandpaper-abrasion method. The transparent glue-paste test was performed 

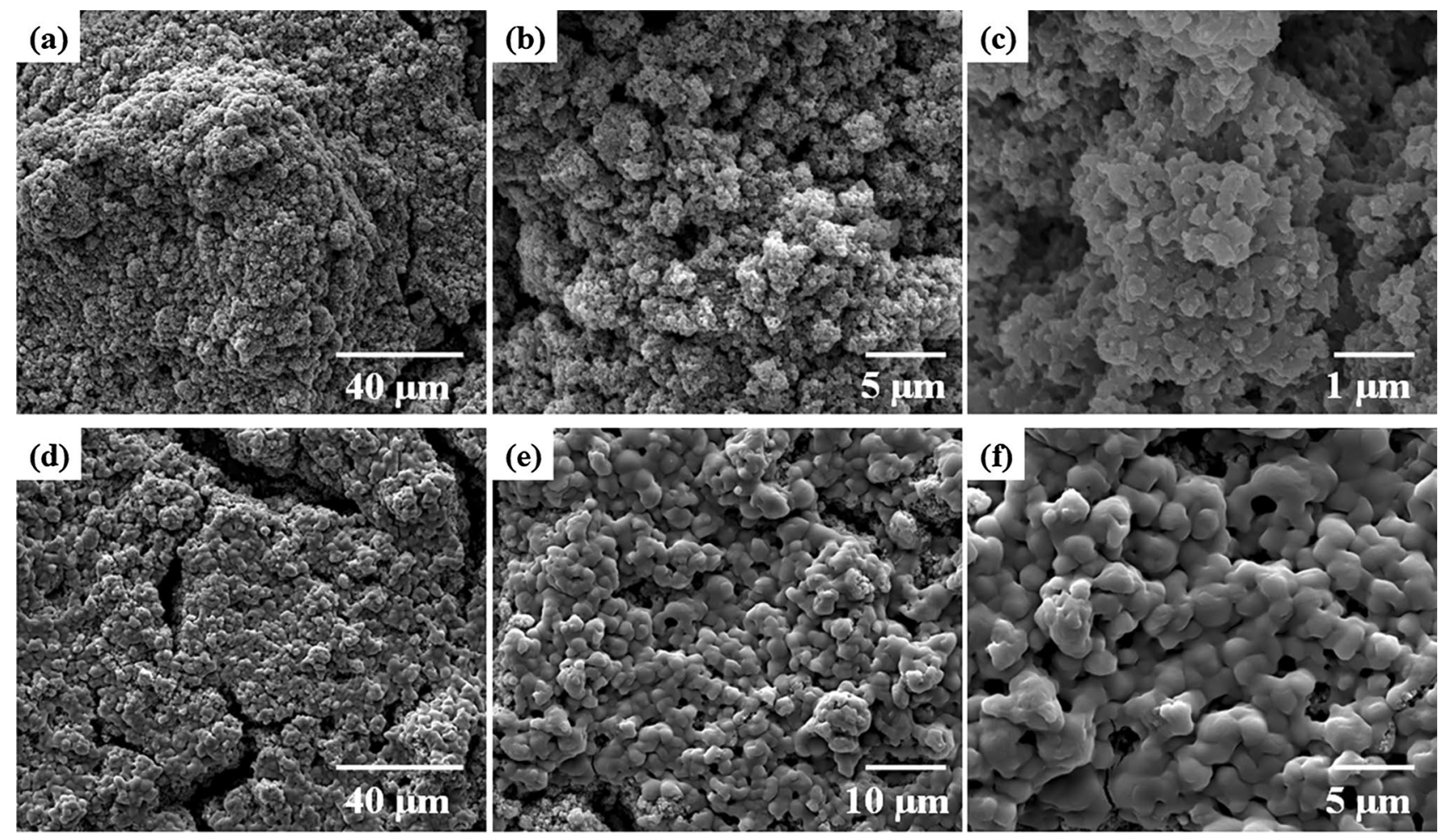

Fig. 3 FESEM micrographs of the coatings: a-c the superhydrophobic coatings (the mass ratio of $\mathrm{SiO}_{2}$ nanoparticles to $\mathrm{TiO}_{2}$ nanoparticles is $1: 2) ; \mathbf{d}-\mathbf{f}$ the coatings (the mass ratio of $\mathrm{SiO}_{2}$ nanoparticles to $\mathrm{TiO}_{2}$ nanoparticles is $1: 1$ )

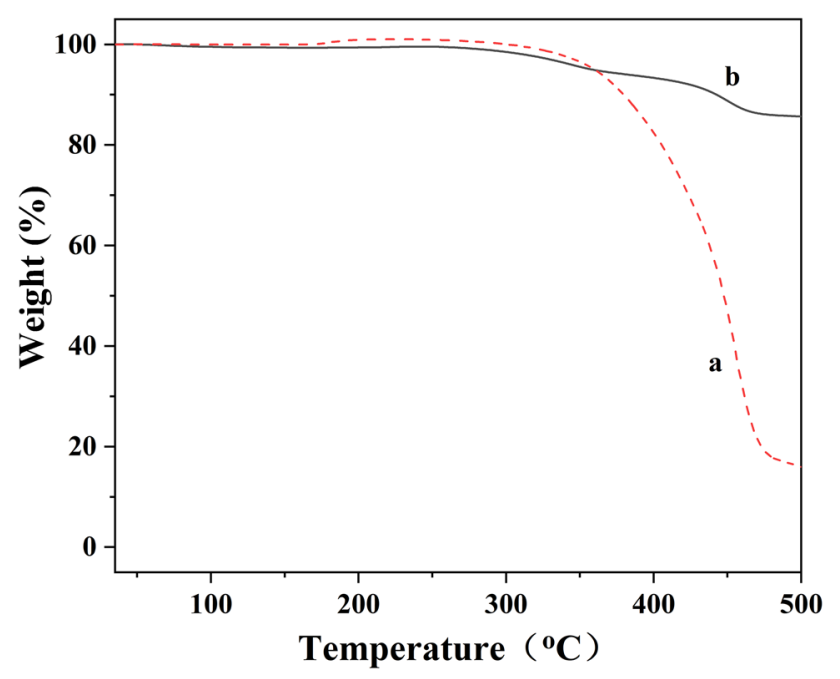

Fig. 4 The TGA curves of the coatings: (a) the SBS coatings; (b) the superhydrophobic coatings

when the superhydrophobic coatings were peeled off by common transparent glue, then the WCA was measured. The finger-touch test was performed when the superhydrophobic coatings were pressed by finger. The superhydrophobic coatings were swept by brush, then the WCA was measured. The experimental schematic diagram of sandpaper-abrasion was shown in Fig. S1. The sample was first placed face-down to sandpaper (standard sandpaper, grit no. 800) and moved for $15 \mathrm{~cm}$ along the ruler under a weight at $100 \mathrm{~g}$, and then the sample was rotated by $90^{\circ}$ (face to the sandpaper) and moved for $15 \mathrm{~cm}$. This operation was repeated 3 times, then the WCA was measured. The coatings coated on glass plates were immersed in 3.5 $w t . \% \mathrm{NaCl}$ solution for a certain time, then taking the glass plates out and dropping water droplets on the coatings to observe their hydrophobicity. Dynamic polarization curve and electrochemical impedance spectroscopy (EIS) were chose to investigate the corrosion resistance of coatings. Both dynamic polarization curve and EIS measurements were carried out using a $3.5 \mathrm{wt} . \% \mathrm{NaCl}$ solution at room temperature. The aluminium plate coated with coatings was used as working electrodes $(1 \mathrm{~cm} \times 1 \mathrm{~cm})$, while the $\mathrm{Ag} / \mathrm{AgCl}$ electrode and platinum fossil $(1 \mathrm{~cm} \times 2 \mathrm{~cm})$ were applied as reference electrode and counter electrode, respectively. The sample was firstly soaking in $\mathrm{NaCl}$ solution for $30 \mathrm{~min}$ till the open circuit potential remained stable. Subsequently, EIS tests were operated at the open circuit potential under the vibration frequency of $0.1 \mathrm{~Hz}$ to $100 \mathrm{kHz}$, the amplitude of $5 \mathrm{mV}$ and the static time of $2 \mathrm{~s}$. The dynamic polarization curve was obtained by sweeping linear scanning voltammetry from -2 to $0 \mathrm{~V}$ with the scan 
Fig. 5 The photograph of the superhydrophobic coatings after annealing at $200^{\circ} \mathrm{C}$ for 3 days (a); photographs of water droplets sitting on the treated superhydrophobic coatings (b, c). Water droplets were dyed blue by methylene blue

\section{(a)}

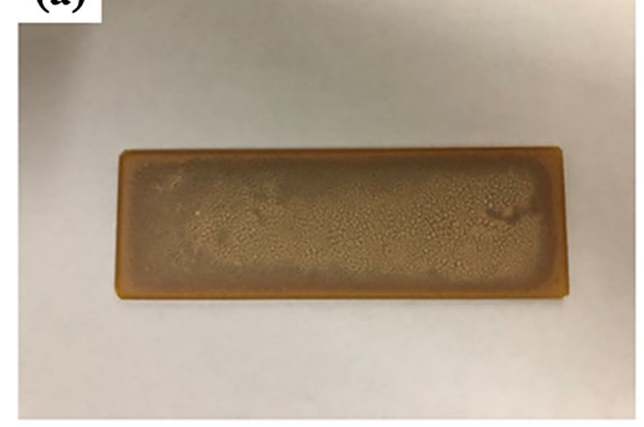

(b)

(c)

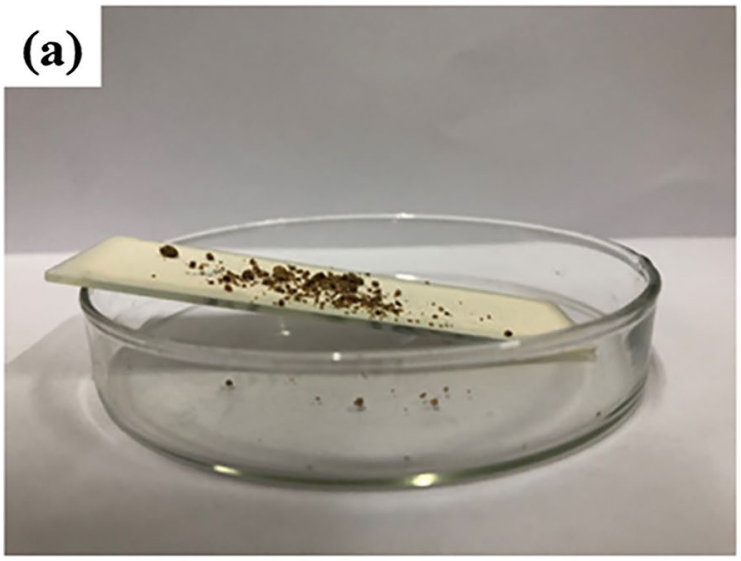

(b)
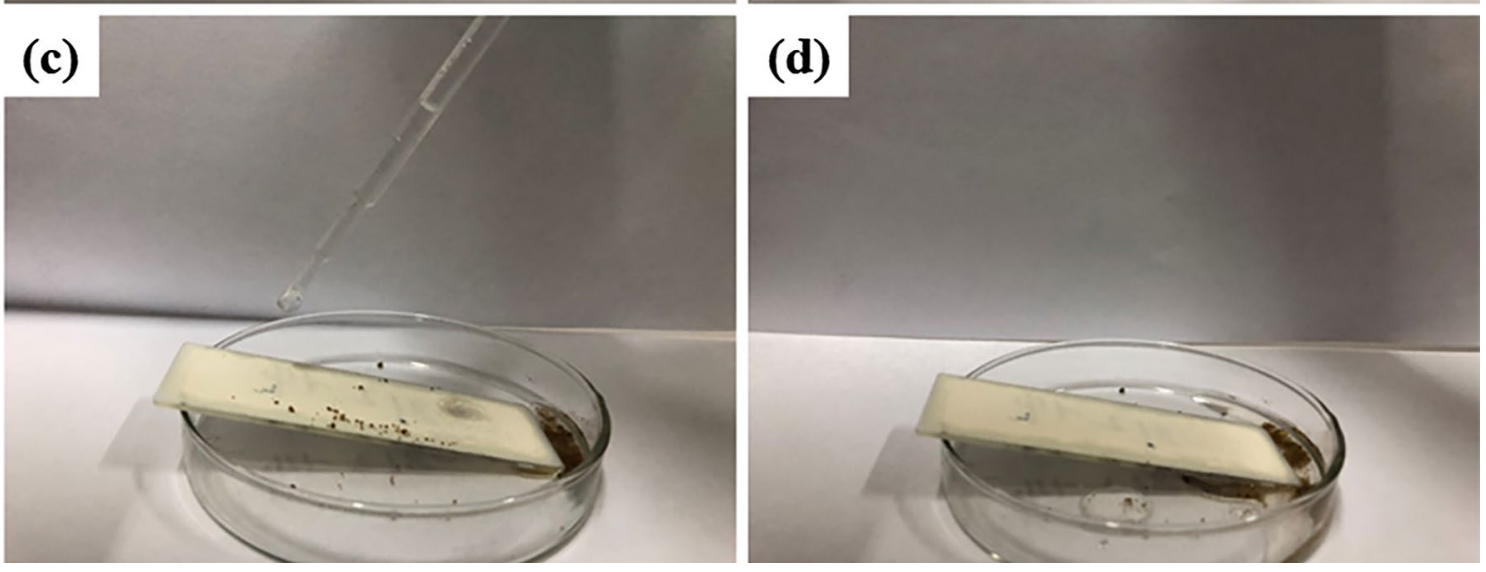

Fig. 6 The self-cleaning test of the superhydrophobic coatings 
Fig. 7 The images illustrate a paper box coated with the superhydrophobic coatings carrying river sands floating on water surface
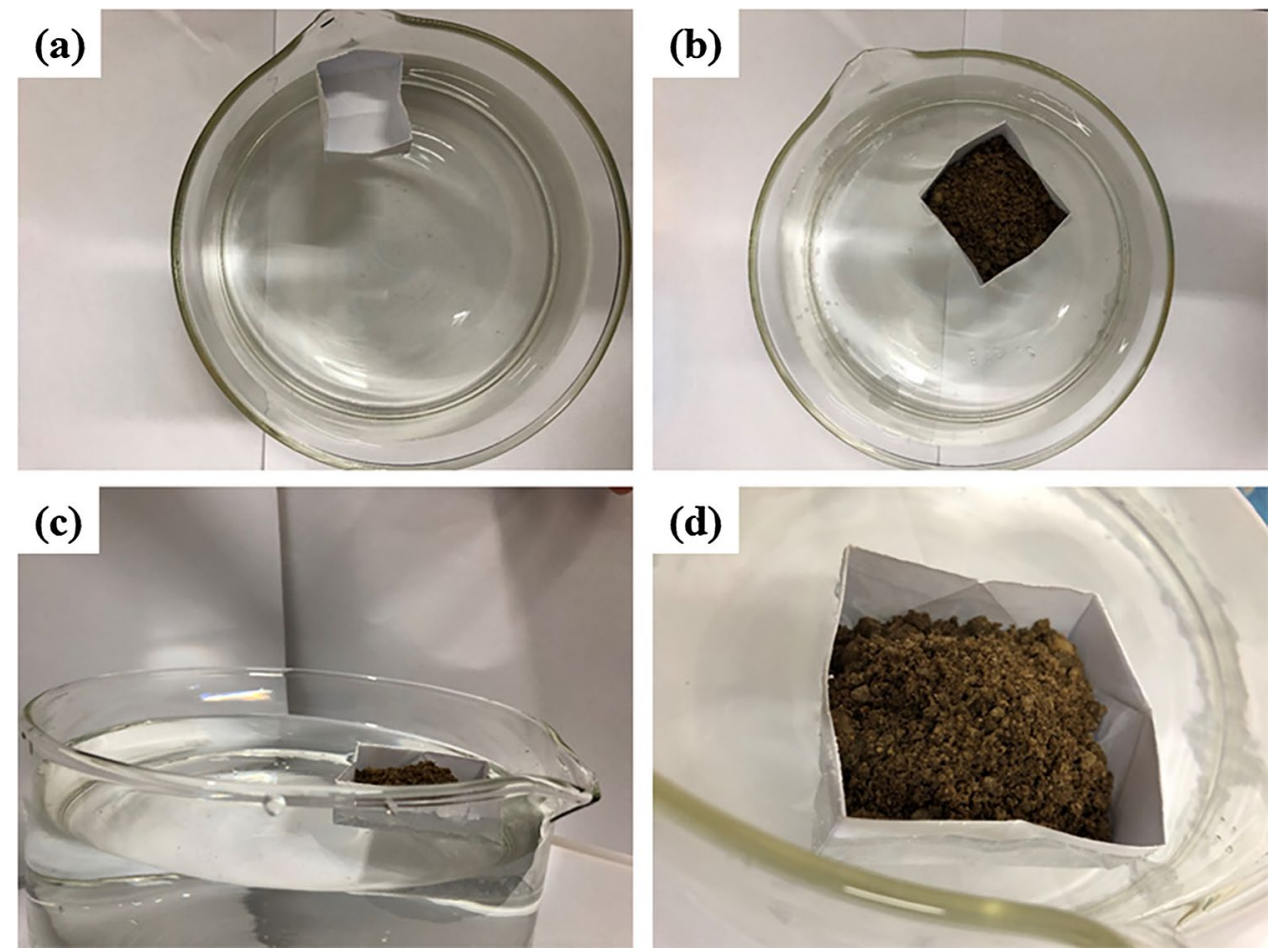

rate of $10 \mathrm{mV} \mathrm{s}^{-1}$. The morphologies of samples before and after corrosion were observed by FESEM.

\section{Results and discussion}

\subsection{Preparation and characterization of the superhydrophobic coatings}

In this work, the superhydrophobic coatings with a remarkable WCA of $154.4^{\circ}$ and contact angle hysteresis of $2.1^{\circ}$ were prepared by mixing SBS and two kinds of nanoparticles of $\mathrm{SiO}_{2}$ and $\mathrm{TiO}_{2}$ when the total mass of the nanoparticles accounted for $80 \%$ of the coatings, and the mass ratio of $\mathrm{SiO}_{2}$ nanoparticles to $\mathrm{TiO}_{2}$ nanoparticles was 1:2. Some substrates, such as glass plate, cotton cloth and aluminium plate, coated with the superhydrophobic coatings, were shown in Fig. 1. A $5 \mu \mathrm{L}$ distilled water-drop profile on the superhydrophobic coatings can be seen from the inset in Fig. 1. The images in Fig. 2 illustrate water droplet bouncing on the tilted superhydrophobic coatings. For easy observation, water droplets were dyed blue by methylene blue. The hydrophobicity of the coatings can be seen from Fig. 2. Figure 3a-c expresse the surface roughness of the superhydrophobic coatings. The composite coatings with different total mass of the nanoparticles, and different mass ratio of $\mathrm{SiO}_{2}$ nanoparticles to $\mathrm{TiO}_{2}$ nanoparticles were prepared in our experiment. For comparison purposes, the coatings with total mass of the nanoparticles of $80 \mathrm{wt} . \%$, and the mass ratio of $\mathrm{SiO}_{2}$ nanoparticles to $\mathrm{TiO}_{2}$ nanoparticles of 1:1 were characterized by FESEM. The surface roughness of this comparative sample was shown in Fig. 3d-f. Although the mass fraction of the nanoparticles is the same in these two coatings, the surface roughness of the superhydrophobic coatings (Fig. $3 a-c$ ) is much higher than the comparative sample (Fig. $3 d-f$ ). From the Fig. 3a-c, we can see very fine multi-scale rough structures. The WCA of the comparative sample is $138.9^{\circ}$, the result also shows that the surface roughness is not enough, and the WCA results are consistent with the FESEM results in our experimental.

\subsection{Thermal stability of the superhydrophobic coatings}

TGA test was used to evaluate the thermal stability of the coatings, and the results are shown in Fig. 4. In Fig. 4a, b, these two coatings had almost no weight loss before 

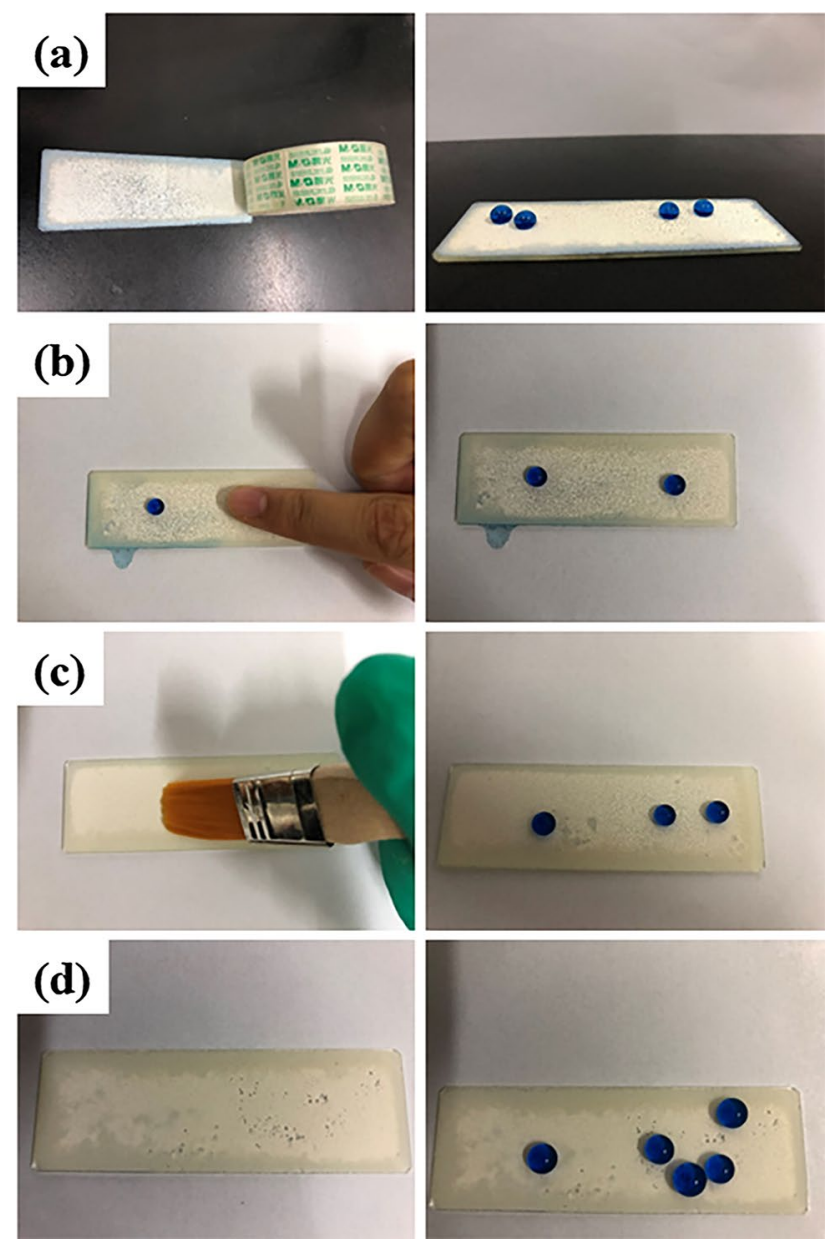

Fig. 8 The superhydrophobic coatings against water droplets after the transparent glue-paste (a), finger-touch (b), brush-sweep (c) and sandpaper-abrasion (d)

$300{ }^{\circ} \mathrm{C}$ in air atmosphere. The two coatings lost nearly 5 wt. $\%$ after $350^{\circ} \mathrm{C}$. The strong mass loss occur between $350^{\circ} \mathrm{C}$ and $480^{\circ} \mathrm{C}$. The results demonstrated that the pure SBS coatings and the superhydrophobic coatings could withstand at high temperature up to $300^{\circ} \mathrm{C}$ in air atmosphere, and had excellent thermal stability from room temperature to $300{ }^{\circ} \mathrm{C}$. To further characterize the heat resistance of the superhydrophobic coatings, they were annealed at $200^{\circ} \mathrm{C}$ for 3 days. The photograph of the superhydrophobic coatings after annealing is shown in Fig. 5 a. The surface of the superhydrophobic coatings turned yellow due to aging. From Fig. 5b, c, We can see that the yellowed coatings are still very hydrophobic, and their WCA is $153.9^{\circ}$. This result also showed that the superhydrophobic coatings had very good thermal stability.

\subsection{The self-cleaning property of the superhydrophobic coatings}

Self-cleaning test was carried out on the superhydrophobic coatings contaminated with river sands (Fig. 6 ). The superhydrophobic coatings show self-cleaning abilities in Fig. 6b, c. The water droplets took away the river sands accompanied by the water droplets rolling. After a while, the surface of the coatings became cleaning, which indicated that our work would be potential for self-cleaning applications.

\subsection{Water repellency of the superhydrophobic coatings in water}

Superhydrophobic surfaces are generally water repellent in water. The images of a square paper box coated with the superhydrophobic coatings carrying river sands in the water were shown in Fig. 7. Because of the superhydrophobic coatings, the water cannot be penetrated into the box inside, and the box can not only float on the water surface but also has striking loading capacity. The box with $0.78 \mathrm{~g}$ could carry more than $30 \mathrm{~g}$ river sands. The loading capacity of the box exceeded $2.38 \mathrm{~g} / \mathrm{cm}^{2}$. The superhydrophobic coatings might be extended to the design of novel superfloating and drag-reducing aquatic devices.

\subsection{Mechanical property of the superhydrophobic coatings}

Surface robustness of the superhydrophobic coatings was tested via four ways, including transparent glue-paste, finger-touch, brush-sweep tests and sandpaper-abrasion. The results are given at Fig. 8 . From the Fig. $8 \mathrm{a}-\mathrm{c}$, we can see that the hydrophobicity of the coatings is remained after being treated by the three ways. The experimental images of sandpaper-abrasion were shown in Fig. S1. Water droplets were dyed by methylene blue and coffee, respectively. From the Fig. S1 and Fig. 8d, surface damage of the coatings is clearly visible. Interestingly, the hydrophobicity of the coatings is almost unaffected by the damage. The results of the surface robustness tests demonstrates good mechanical stability of the superhydrophobic coatings, 

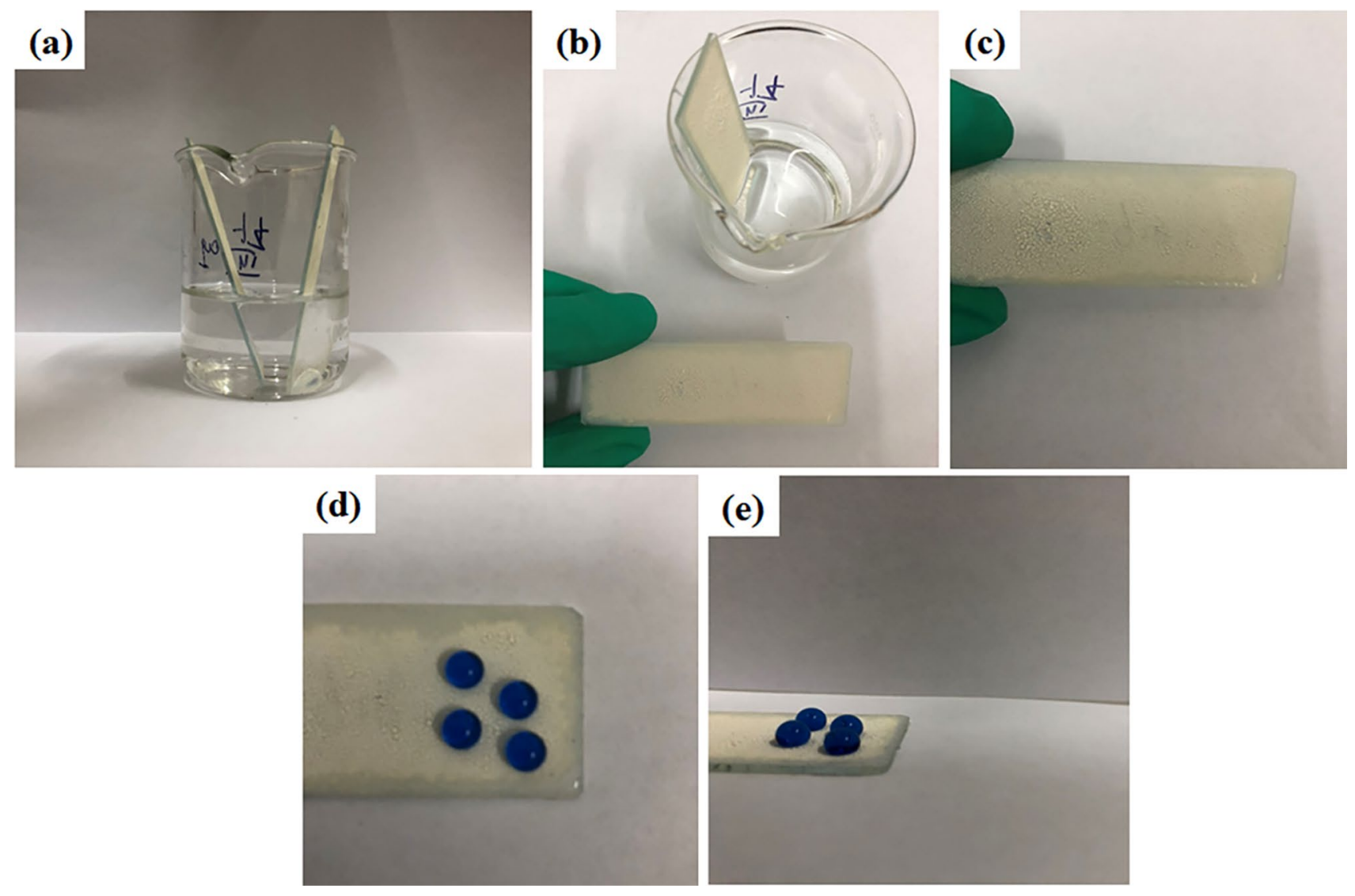

Fig. 9 The superhydrophobic coatings against water droplets after immersing in $3.5 \mathrm{wt} . \% \mathrm{NaCl}$ solution for 3 days

which means the coatings have significant application potential in practical application.

\subsection{Anti-corrosion property of the superhydrophobic coatings}

Figure 9 displays the superhydrophobic coatings against water droplets after immersing in $3.5 \mathrm{wt} . \% \mathrm{NaCl}$ solution for 3 days. The hydrophobicity of the coatings was remained when they were taken out directly from the $\mathrm{NaCl}$ solution. In fact, many superhydrophobic surfaces show superhydrophobicity only in the dry state, and may lose their superhydrophobicity after being soaked in water for a certain period of time (wet state). According to Cassie model, air trapped in the solid surface plays an important role on superhydrophobicity. The decrease in hydrophobicity of many superhydrophobic surfaces (wet state) is attributed to air being replaced by water. The superhydrophobic coatings in this work could withstand $\mathrm{NaCl}$ solution soak for 3 days probably because of the fine multi-scale rough structures and chemical composition of their surfaces. Figure 10a-c show the morphology of the superhydrophobic coatings after being immersed in 3.5 wt.\% $\mathrm{NaCl}$ solution for 3 days. Similar to Fig. 3, for comparison, the comparative sample was also immersed in $3.5 \mathrm{wt} . \%$ $\mathrm{NaCl}$ solution for 3 days, and then the surface morphology of this comparative sample was also characterized by FESEM (Fig. 10d-f). The NaCl solution volatilized and dried, leaving a larger solid of $\mathrm{NaCl}$ (red dotted circle in Fig. 10b). In Fig. 10a-c, it can be observed that the morphology of the coatings has no obvious difference compared with the uncorroded coatings (Fig. $3 a-c$ ), suggesting that the superhydrophobic coatings have good corrosion resistance. However, $\mathrm{NaCl}$ powders with large area appeared on the surface of the comparative sample. The difference in the form of $\mathrm{NaCl}$ on the surface of these two coatings also reflects the good corrosion resistance of the superhydrophobic coatings from the side. To study whether the 

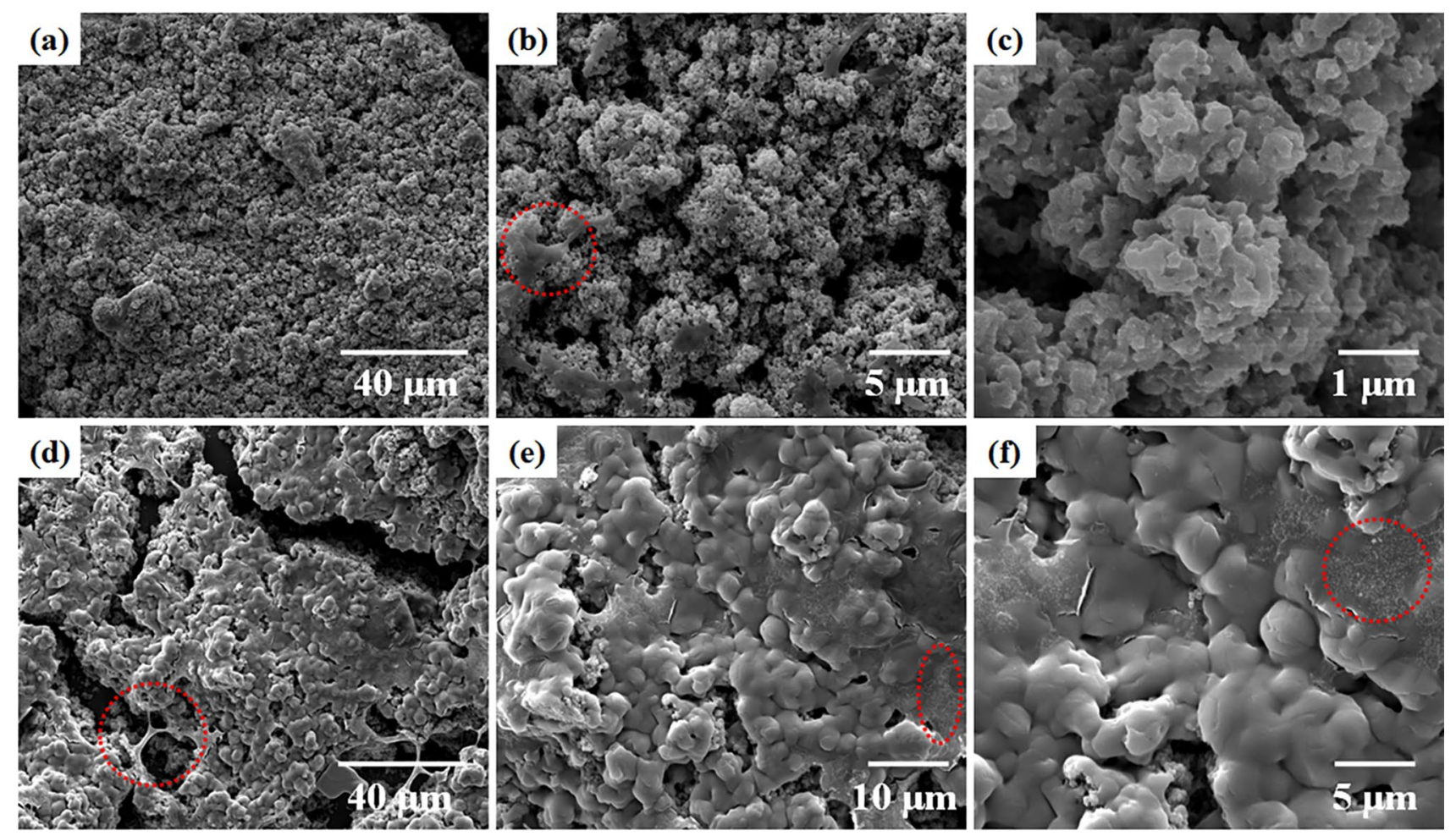

Fig. 10 FESEM micrographs of the coatings after being immersed in 3.5 wt. $\% \mathrm{NaCl}$ solution for 3 days: a-c the superhydrophobic coatings (the mass ratio of $\mathrm{SiO}_{2}$ nanoparticles to $\mathrm{TiO}_{2}$ nanoparticles

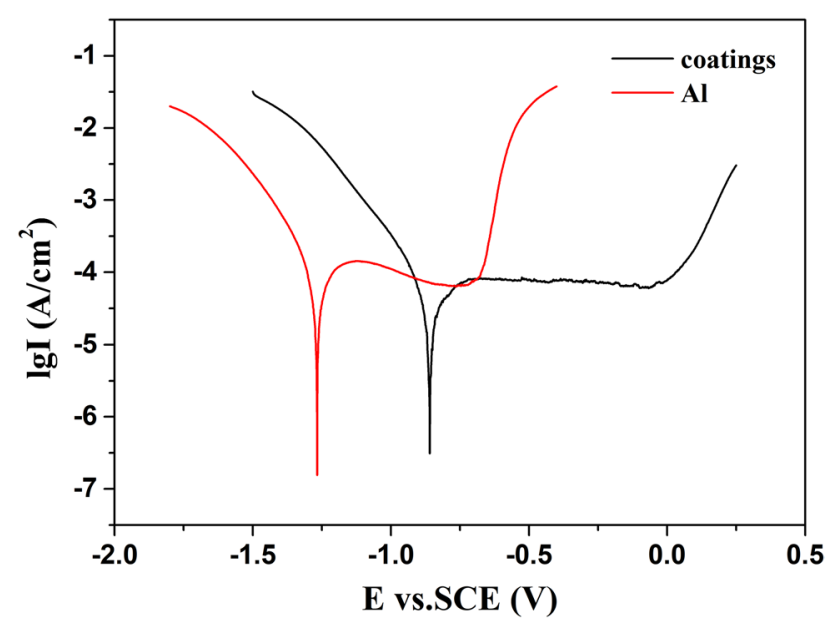

Fig. 11 Dynamic polarization curves of aluminium and the superhydrophobic coatings coated on aluminium plate is $1: 2$ ); $\mathbf{d}-\mathbf{f}$ the coatings (the mass ratio of $\mathrm{SiO}_{2}$ nanoparticles to $\mathrm{TiO}_{2}$ nanoparticles is $1: 1$ )

chemical composition of the coatings surfaces changes before and after soaking, they were examined by EDS. The results were shown in Table S1. The EDS spectra roughly revealed the chemical composition of the coatings surfaces. The possible reason is that more polymers migrate to the surface of the superhydrophobic coatings compared with the comparative sample after immersion in $3.5 \mathrm{wt} . \% \mathrm{NaCl}$ solution for 3 days.

Figure 11 displays the dynamic polarization curves of aluminium and the superhydrophobic coatings coated on aluminium plate measured in $3.5 \mathrm{wt} . \% \mathrm{NaCl}$ solution. The corrosion potential $\left(\mathrm{E}_{\text {corr }}\right)$ and corrosion current $\left(\mathrm{I}_{\text {corr }}\right)$ were obtained by calculated and were given in Table 1 . The $\mathrm{E}_{\text {corr }}$ of the coatings coated aluminium plate is $-0.859 \mathrm{~V}$, which is more positive than that of aluminium $(-1.267 \mathrm{~V})$. $\mathrm{I}_{\text {corr }}$ of aluminium plate changed from $1.106 \times 10^{-4} \mathrm{~A} \cdot \mathrm{cm}^{-2}$ to about $4.956 \times 10^{-5} \mathrm{~A} \mathrm{~cm}^{-2}$ for the superhydrophobic 

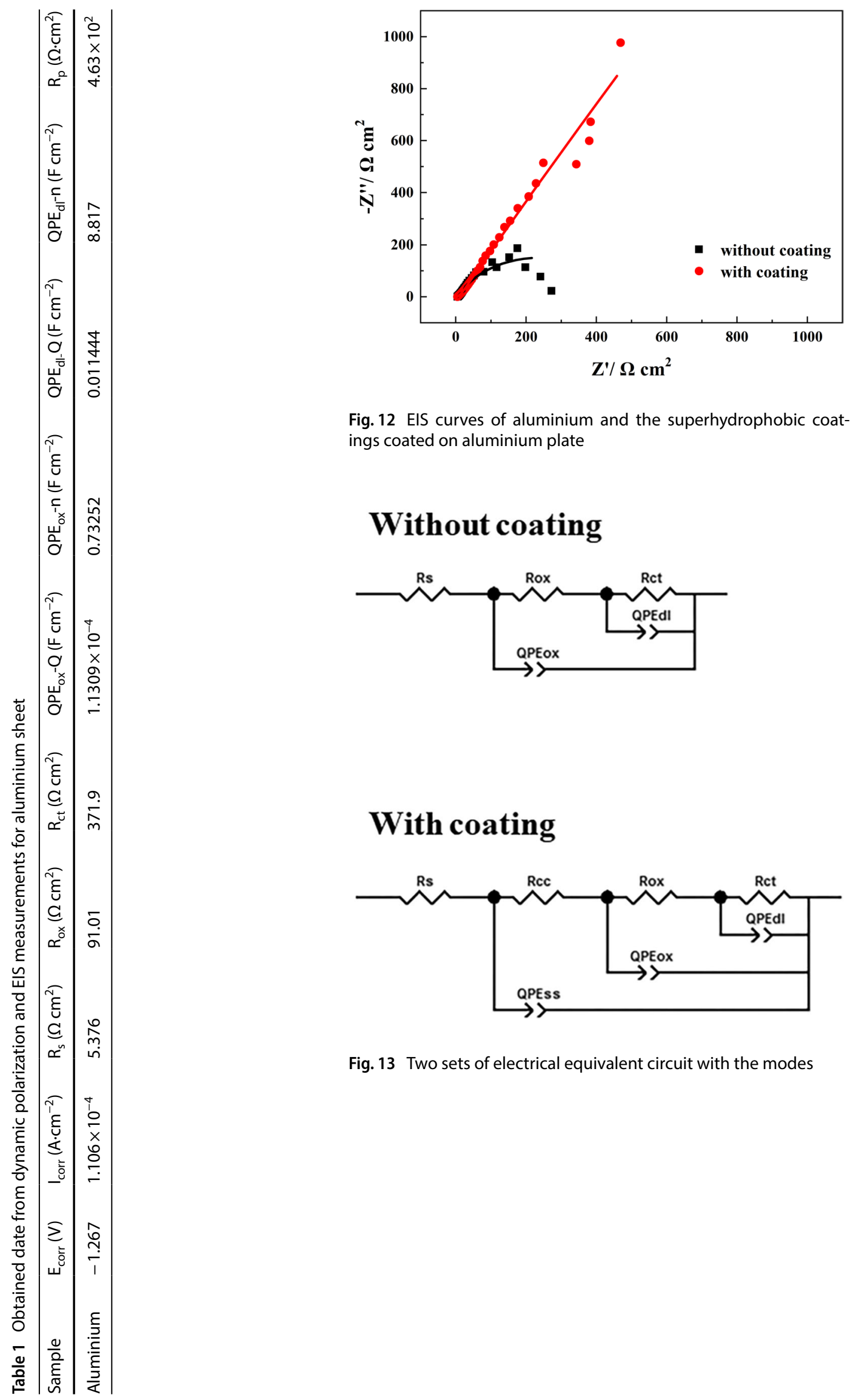

Fig. 12 EIS curves of aluminium and the superhydrophobic coatings coated on aluminium plate

\section{Without coating}

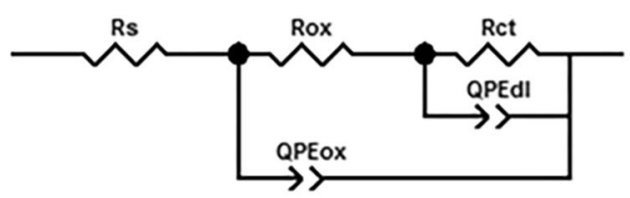

With coating

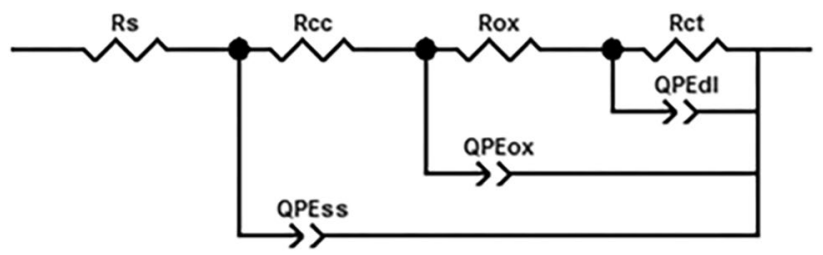

Fig. 13 Two sets of electrical equivalent circuit with the modes 
coatings coated aluminium plate, indicating that the superhydrophobic coatings improve the corrosion resistance of aluminium.

EIS was used to evaluate the anti-corrosion performance of the superhydrophobic coatings. Figure 12 displays the Nyquist plots of aluminum sheet with and without the superhydrophobic coatings, respectively. It is clear that the plots of bare aluminum sheet exhibit a capacitive loop inferring the presence of electrochemical corrosion reaction; but the one with the superhydrophobic coatings delivers a spike, an indication of noteworthy anti-corrosion performance. As shown in Fig. 13, two sets of electrical equivalent circuit with the modes of $\left.\mathrm{R}_{\mathrm{S}}\left(\mathrm{QPE}_{\mathrm{ox}} / /\left(\mathrm{R}_{\mathrm{ox}}\left(\mathrm{QPE}_{\mathrm{dl}} / / \mathrm{R}_{\mathrm{ct}}\right)\right)\right)\right)$ and $\mathrm{R}_{\mathrm{S}}\left(\mathrm{QPE}_{\mathrm{cc}} / /\left(\mathrm{R}_{\mathrm{cc}}\left(\mathrm{QPE} \mathrm{Ex}_{\mathrm{ox}} / /\right.\right.\right.$ $\left.\left.\left(R_{\mathrm{ox}}\left(\mathrm{QPE}_{\mathrm{dl}} / / \mathrm{R}_{\mathrm{ct}}\right)\right)\right)\right)$, respectively, are used to simulate the as-obtained Nyquist plots, where "//" indicates parallel, " $\mathrm{R}_{\mathrm{s}}$ " means solution resistance. "QPE ${ }_{\mathrm{cc}}$ ", "QPE $\mathrm{ox}_{\mathrm{ox}}$ " and " $Q P E_{d l}$ " are the constant phase element of the superhydrophobic coatings, oxide layer of aluminum sheet and the electric double layer capacitor of aluminum sheet, respectively. " $\mathrm{R}_{\mathrm{cc}}$," " $\mathrm{R}_{\mathrm{ox}}$ " and " $\mathrm{R}_{\mathrm{ct}}$ " indicate the resistance of the superhydrophobic coatings, oxide layer of aluminum sheet and charge transfer resistance, respectively. The polarization resistance $R_{\mathrm{p}}$, a pivotal criterion to assess the anti-corrosion performance, is defined as the sum of the superhydrophobic coatings resistance $\left(R_{c c}\right)$ and oxide layer resistance $\left(R_{o x}\right)$ and charge transfer resistance $\left(R_{c t}\right)\left(R_{p}=R_{c c}+R_{o x}+R_{c t}\right)$ [43]. The fitting data is shown in Tables 1 and 2. The aluminum sheet with the superhydrophobic coatings exerts a $R_{\mathrm{p}}$ value of $8.87 \times 10^{4} \Omega \mathrm{cm}^{2}$, which significantly triumphs over the bare aluminum sheet $\left(4.63 \times 10^{2} \Omega \mathrm{cm}^{2}\right)$. Such fitting results shed light on the promising anti-corrosion characteristic of the superhydrophobic coatings.

\subsection{Oil/water separation of the superhydrophobic coatings}

Superhydrophobic porous materials have potential for use in the oil/water separation. Here, oil/water separation test was performed to investigate the potential of the filter paper coated with the superhydrophobic coatings for application in oil/water separation. Figure 14 shows the separation procedure for a mixture containing DCM and water. The DCM permeated through the coated filter paper under gravity and was collected in the beaker below, whereas the water was retained in the glass tube above the coated filter paper. The results reveal the ability of the coated filter paper to separate oil/water mixtures. 

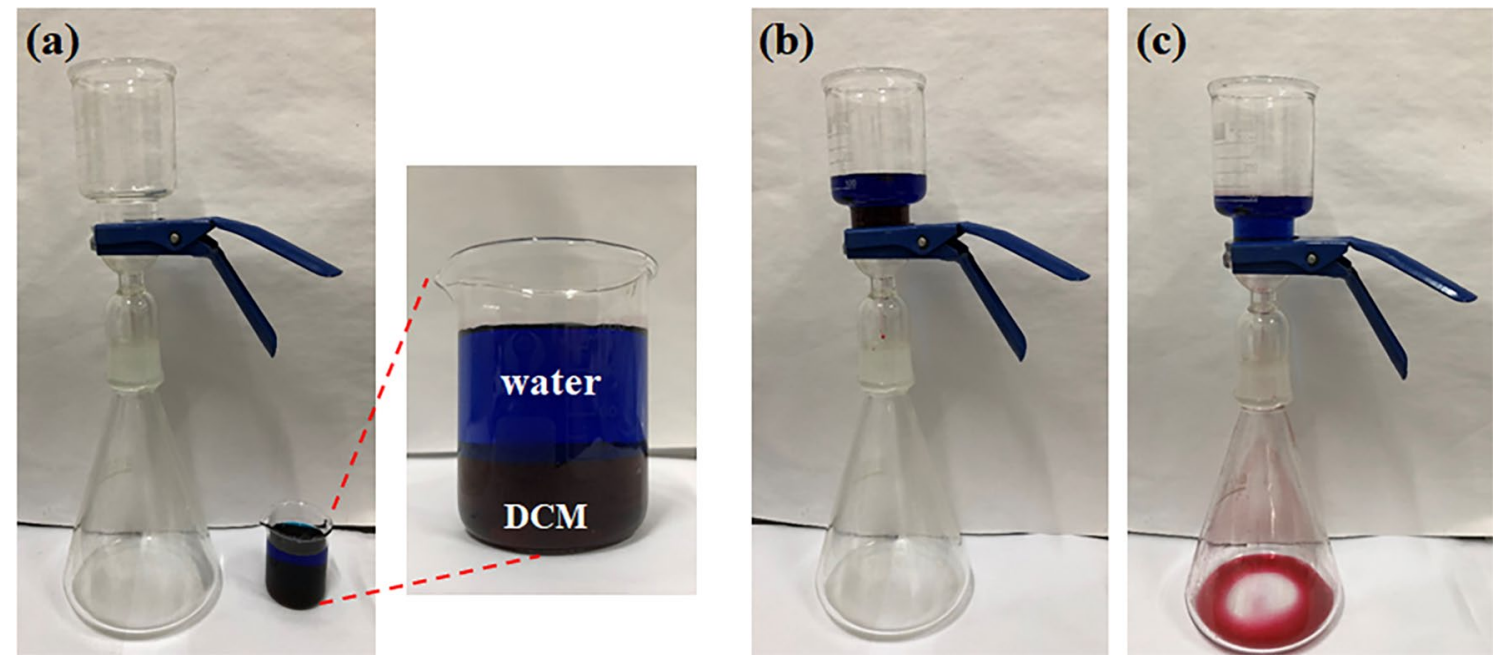

Fig. 14 The images illustrate oil/water separation of the superhydrophobic coatings. Water droplets were dyed blue by methylene blue. DCM was dyed red by oil red $\mathrm{O}$

\section{Conclusions}

In summary, the multi-scale nano/microstructures were induced by SBS and two kinds of nanoparticles of $\mathrm{SiO}_{2}$ and $\mathrm{TiO}_{2}$ and the robust and anti-corrosive superhydrophobic coatings were successfully fabricated. The coatings are superhydrophobic when the total mass of the nanoparticles accounts for $80 \%$ of the coatings, and the mass ratio of $\mathrm{SiO}_{2}$ nanoparticles to $\mathrm{TiO}_{2}$ nanoparticles is $1: 2$. The superhydrophobic coatings exhibited excellent thermal stability, mechanical stability and self-cleaning property. The electrochemical experiment shows that the obtained optimal superhydrophobic coatings can significantly improve the corrosion resistance of aluminium. Besides, the superhydrophobic coatings could be used to oil/water separation. The superhydrophobic coatings give a promising prospect for practical applications in a broad range of fields based on their large-scale and low-cost fabrication method.

Acknowledgements This work was supported by Research Project of Hubei Provincial Department of Education (No. Q20171108), Youth science and technology backbone training program of the Wuhan University of Science and Technology (No. 2017xz010), and Key Laboratory of Hubei Province for Coal Conversion and New Carbon Materials (Wuhan University of Science and Technology) (No. WKDM201711).

\section{Compliance with ethical standards}

Conflict of interest The authors declare that they have no conflict of interest.

\section{References}

1. Zhou Q, Yan B, Xing T, Chen G (2019) Fabrication of superhydrophobic caffeic acid/Fe@cotton fabric and its oil-water separation performance. Carbohydr Polym 203:1-9

2. Yang J, Wang H, Tao Z, Liu X, Wang Z, Yue R, Cui Z (2019) 3D superhydrophobic sponge with a novel compression strategy for effective water-in-oil emulsion separation and its separation mechanism. Chem Eng J 359:149-158

3. Wang J, Wang H (2019) Ultra-hydrophobic and mesoporous silica aerogel membranes for efficient separation of surfactantstabilized water-in-oil emulsion separation. Sep Purif Technol 212:597-604

4. Seeharaj P, Pasupong P, Detsri E, Damrongsak P (2018) Superhydrophobilization of $\mathrm{SiO}_{2}$ surface with two alkylsilanes for an application in oil/water separation. J Mater Sci 53(7):4828-4839

5. Salehabadi S, Seyfi J, Hejazi I, Davachi SM, Naeini AH, Khakbaz M (2017) Nanosilica-decorated sponges for efficient oil/water separation: role of nanoparticle's type and concentration. J Mater Sci 52:7017-7027

6. Jiang C, Liu W, Yang M, Liu C, He S, Xie Y, Wang Z (2019) Robust multifunctional superhydrophobic fabric with UV induced reversible wettability, photocatalytic self-cleaning property, and oil-water separation via thiol-ene click chemistry. Appl Surf Sci 463:34-44

7. Zhao X, Li J, Li Q, Qiao L, Zhang L, Liu Z, Yang C (2018) Fabrication of a scratch and heat resistant superhydrophobic $\mathrm{SiO}_{2}$ surface with self-cleaning and semi-transparent performance. RSC Adv 8(44):25008-25013

8. Xie W-Y, Song F, Wang X-L, Wang Y-Z (2017) Development of copper phosphate nanoflowers on soy protein toward a superhydrophobic and self-cleaning film. ACS Sustain Eng 5(1):869-875

9. Vilaro I, Yague JL, Borros S (2017) Superhydrophobic copper surfaces with anticorrosion properties fabricated by solventless CVD methods. ACS Appl Mater Interfaces 9(1):1057-1065

10. Qian H, Xu D, Du C, Zhang D, Li X, Huang L, Deng L, Tu Y, Mol JMC, Terryn HA (2017) Dual-action smart coatings with a selfhealing superhydrophobic surface and anti-corrosion properties. J Mater Chem A 5(5):2355-2364 
11. Wu C, Liu Q, Chen R, Liu J, Zhang H, Li R, Takahashi K, Liu P,

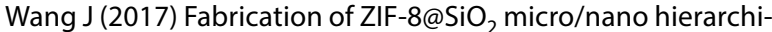
cal superhydrophobic surface on AZ31 magnesium alloy with impressive corrosion resistance and abrasion resistance. ACS Appl Mater Interfaces 9(12):11106-11115

12. Li J, Lu S, Xu W, He G, Yu T, Cheng Y, Wu B (2018) Fabrication of stable Ni- $\mathrm{Al}_{4} \mathrm{Ni}_{3}-\mathrm{Al}_{2} \mathrm{O}_{3}$ superhydrophobic surface on aluminum substrate for self-cleaning, anti-corrosive and catalytic performance. J Mater Sci 53(2):1097-1109

13. Zuo Z, Liao R, Song X, Zhao X, Yuan Y (2018) Improving the anti-icing/frosting property of a nanostructured superhydrophobic surface by the optimum selection of a surface modifier. RSC Adv 8(36):19906-19916

14. Wu X, Chen Z (2018) A mechanically robust transparent coating for anti-icing and self-cleaning applications. J Mater Chem A 6:16043-16052

15. Wang N, Tang L, Tong W, Xiong D (2018) Fabrication of robust and scalable superhydrophobic surfaces and investigation of their anti-icing properties. Mater Des 156:320-328

16. Lomga J, Varshney P, Nanda D, Satapathy M, Mohapatra SS, Kumar A (2017) Fabrication of durable and regenerable superhydrophobic coatings with excellent self-cleaning and antifogging properties for aluminum surfaces. J Alloys Compd 702:161-170

17. Shang Q, Zhou Y (2016) Fabrication of transparent superhydrophobic porous silica coating for self-cleaning and anti-fogging. Ceram Int 42(7):8706-8712

18. Chauhan P, Kumar A, Bhushan B (2019) Self-cleaning, stainresistant and anti-bacterial superhydrophobic cotton fabric prepared by simple immersion technique. J Colloid Interface Sci 535:66-74

19. Zhou S, Wang F, Balachandran S, Li G, Zhang X, Wang R, Liu P, Ding Y, Zhang S, Yang M (2017) Facile fabrication of hybrid PA6-decorated $\mathrm{TiO}_{2}$ fabrics with excellent photocatalytic, antibacterial, UV light-shielding, and super hydrophobic properties. RSC Adv 7(83):52375-52381

20. Tuo Y, Chen W, Zhang H, Li P, Liu X (2018) One-step hydrothermal method to fabricate drag reduction superhydrophobic surface on aluminum foil. Appl Surf Sci 446:230-235

21. Liu Y, Gu H, Jia Y, Liu J, Zhang $H$, Wang R, Zhang B, Zhang $H$, Zhang Q (2019) Design and preparation of biomimetic polydimethylsiloxane (PDMS) films with superhydrophobic, selfhealing and drag reduction properties via replication of shark skin and SI-ATRP. Chem Eng J 356:318-328

22. Foorginezhad S, Zerafat MM (2019) Fabrication of stable fluorine-free superhydrophobic fabrics for anti-adhesion and selfcleaning properties. Appl Surf Sci 464:458-471

23. Khayet M, Wang R (2018) Mixed matrix polytetrafluoroethylene/polysulfone electrospun nanofibrous membranes for water desalination by membrane distillation. ACS Appl Mater Interfaces 10(28):24275-24287

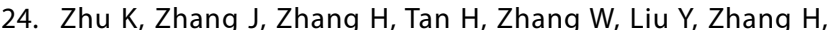
Zhang Q (2018) Fabrication of durable superhydrophobic coatings based on a novel branched fluorinated epoxy. Chem Eng J 351:569-578

25. Hou Y, Wang Z, Guo J, Shen H, Zhang H, Zhao N, Zhao Y, Chen L, Liang S, Jin Y, Xu J (2015) Facile fabrication of robust superhydrophobic porous materials and their application in oil/ water separation. J Mater Chem A 3(46):23252-23260

26. Jia S, Deng S, Luo S, Qing Y, Yan N, Wu Y (2019) Texturing commercial epoxy with hierarchical and porous structure for robust superhydrophobic coatings. Appl Surf Sci 466:84-91

27. Zhu Y, He Y, Yang D-Q, Sacher E (2018) A facile method to prepare mechanically durable super slippery polytetrafluoroethylene coatings. Colloids Surf A 556:99-105
28. Zhang H, Hou C, Song L, Ma Y, Ali Z, Gu J, Zhang B, Zhang H, Zhang Q (2018) A stable 3D sol-gel network with dangling fluoroalkyl chains and rapid self-healing ability as a long-lived superhydrophobic fabric coating. Chem Eng J 334:598-610

29. Yoo D, Kim $Y$, Min $M$, Ahn GH, Lien D-H, Jang J, Jeong $H$, Song $Y$, Chung S, Javey A, Lee T (2018) Highly reliable superhydrophobic protection for organic field-effect transistors by fluoroalkylsilanecoated $\mathrm{TiO}_{2}$ nanoparticles. ACS Nano 12(11):11062-11069

30. Li X, Cao M, Shan H, Handan Tezel F, Li B (2019) Facile and scalable fabrication of superhydrophobic and superoleophilic PDMS-coPMHS coating on porous substrates for highly effective oil/water separation. Chem Eng J 358:1101-1113

31. Liao X, Li H, Zhang L, Su X, Lai X, Zeng X (2018) Superhydrophobic $\mathrm{mGO} / \mathrm{PDMS}$ hybrid coating on polyester fabric for oil/water separation. Prog Org Coat 115:172-180

32. Liu H, Huang J, Chen Z, Chen G, Zhang K-Q, Al-Deyab SS, Lai Y (2017) Robust translucent superhydrophobic PDMS/PMMA film by facile one-step spray for self-cleaning and efficient emulsion separation. Chem Eng J 330:26-35

33. Zhu B, Liu J, Chen Y, Liu Y, Yang Z, Zhang Z (2017) Superhydrophobic coating with multiscale structure based on crosslinked silanized polyacrylate and nanoparticles. Surf Coat Technol 331:40-47

34. Zhang X, Liu Z, Zhang X, Li Y, Wang H, Wang J, Zhu Y (2018) Highadhesive superhydrophobic litchi-like coatings fabricated by in situ growth of nano-silica on polyethersulfone surface. Chem Eng J 343:699-707

35. Zhao Z, Wang H, Liu Z, Zhang X, Zhang W, Chen X, Zhu Y (2019) Durable fluorine-free superhydrophobic polyethersulfone (PES) composite coating with uniquely weathering stability, anti-corrosion and wear-resistance. Prog Org Coat 127:16-26

36. Zhu Q, Yu Y, Wu Q-Y, Gu L (2017) Construction of renewable superhydrophobic surfaces via thermally induced phase separation and mechanical peeling. Chin J Chem Phys 30(2):219-224

37. Zhang H, Lu X, Xin Z, Zhang W, Zhou C (2018) Preparation of superhydrophobic polybenzoxazine $/ \mathrm{SiO}_{2}$ films with self-cleaning and ice delay properties. Prog Org Coat 123:254-260

38. Liu S, Zhou SB, Xu Y (2018) Evaluation of cracking properties of SBS-modified binders containing organic montmorillonite. Constr Build Mater 175:196-205

39. Si J, Jia Z, Wang J, Yu X, Li Y, Dong F, Jiang R (2018) Comparative analysis of cold-mixed epoxy and epoxy SBS-modified asphalts: curing rheology, thermal, and mechanical properties. Constr Build Mater 176:165-171

40. Sun W, Wang L, Yang Z, Li S, Wu T, Liu G (2017) Fabrication of polydimethylsiloxane-derived superhydrophobic surface on aluminium via chemical vapour deposition technique for corrosion protection. Corros Sci 128:176-185

41. Wang G, Zeng Z, Chen J, Xu M, Zhu J, Liu S, Ren T, Xue Q (2016) Ultra low water adhesive metal surface for enhanced corrosion protection. RSC Adv 6(47):40641-40649

42. Huang Y, Yi S, Lv Z, Huang C (2016) Facile fabrication of superhydrophobic coatings based on two silica sols. Colloid Polym Sci 294(9):1503-1509

43. Cho E-C, Chang-Jian C-W, Chen H-C, Chuang K-S, Zheng J-H, Hsiao Y-S, Lee K-C, Huang J-H (2017) Robust multifunctional superhydrophobic coatings with enhanced water/oil separation, selfcleaning, anti-corrosion, and anti-biological adhesion. Chem Eng J 314:347-357

Publisher's Note Springer Nature remains neutral with regard to jurisdictional claims in published maps and institutional affiliations. 